\title{
1 Effects of the bacterial algicide IRI-160AA on cellular morphology of harmful
}

\section{2 dinoflagellates}

3

4 Kaytee L. Pokrzywinski ${ }^{\mathrm{a}, \mathrm{c}}$, Charles L. Tilney ${ }^{\mathrm{a}, \mathrm{d}}$, Shannon Modla ${ }^{\mathrm{b}}$, Jeffery L. Caplan ${ }^{\mathrm{b}}$, Jean Ross ${ }^{\mathrm{b}}$, 5 Mark E. Warner ${ }^{\mathrm{a}} \&$ Kathryn J. Coyne ${ }^{\mathrm{a}, 1}$

6

$7{ }^{\mathrm{a} C}$ College of Earth, Ocean, and Environment, University of Delaware, 700 Pilottown Road,

8 Lewes, DE 19958, USA

9

$10{ }^{\mathrm{b}}$ Biomaging Center, Delaware Biotechnology Institute, University of Delaware, 15 Innovation

11 Way, Newark, DE 19711, USA

12

$13{ }^{\mathrm{c}}$ Present address: Engineer Research and Development Center, U.S. Army Corps of Engineers,

143909 Halls Ferry Rd, Vicksburg, MS 39180

15

16 dPresent address: FWC Fish \& Wildlife Research Institute, St. Petersburg, FL 33701

17

18

19 Algicide impacts morphology in dinophyta

20

21

$22{ }^{3}$ Corresponding author, E-mail: kcoyne@udel.edu; tel.: +1 302645 4236; fax: +1 302645 4007,

23700 Pilottown Rd. / Lewes, DE 19958

24 


\section{Abstract}

26 The algicide, IRI-160AA, induces mortality in dinoflagellates but not other species of algae,

27 suggesting that a shared characteristic or feature renders this class of phytoplankton vulnerable to

28 the algicide. In contrast to other eukaryotic species, the genome of dinoflagellates is stabilized

29 by high concentrations of divalent cations and transition metals and contains large amounts of

30 DNA with unusual base modifications. These distinctions set dinoflagellates apart from other

31 phytoplankton and suggest that the nucleus may be a dinoflagellate-specific target for IRI-

32 160AA. In this study, morphological and ultrastructural changes in three dinoflagellate species,

33 Prorocentrum minimum, Karlodinium veneficum and Gyrodinium instriatum, were evaluated

34 after short-term exposure to IRI-160AA using super resolution structured illumination

35 microscopy (SR-SIM) and transmission electron microscopy (TEM). Exposure to the algicide

36 resulted in cytoplasmic membrane blebbing, differing chloroplast morphologies, nuclear

37 expansion, and chromosome expulsion and/or destabilization. TEM analysis showed that

38 chromosomes of algicide-treated $K$. veneficum appeared electron dense with fibrous protrusions.

39 In algicide-treated P. minimum and G. instriatum, chromosome decompaction occurred, while

40 for $P$. minimum, nuclear expulsion was also observed for several cells. Results of this

41 investigation demonstrate that exposure to the algicide destabilizes dinoflagellate chromosomes,

42 although it was not clear if the nucleus was the primary target of the algicide or if the observed

43 effects on chromosomal structure were due to downstream impacts. In all cases, changes in

44 cellular morphology and ultrastructure were observed within two hours, suggesting that the

45 algicide may be an effective and rapid approach to mitigate dinoflagellate blooms.

46 Key words: dinoflagellate; chromosome decompaction; nucleus; cell cycle inhibition; algicide;

47 morphology 


\section{Introduction}

Bacteria are often seen in close association with harmful algal blooms (HABs) and may

51 play an important role in regulating bloom dynamics (Kim et al., 1998; Mayali and Azam, 2004;

52 Bidle and Falkowski, 2004; Liu et al., 2008a; Yoshinaga et al., 2010; Inaba et al., 2014) by

53 enhancing growth (Fukami et al., 1997; Liu et al., 2008b) or through production of algicidal

54 compounds (Sakata et al., 2011; Zheng et al., 2011; Pokrzywinski et al., 2012; Li et al., 2014).

55 Bacteria with algicidal properties often have varying levels of specificity, effective against a

56 single species or genus (e.g. Li et al., 2014) or with activity against a broad range of

57 phytoplankton species (e.g. Lovejoy et al., 1998; Hare et al., 2005; Pokrzywinski et al., 2012).

58 Algicides that are affective against a narrow group of HAB species likely target a common

59 feature or characteristic shared by those species. An example would be the growth inhibitory

60 effects of L-Lysine and L-Lysine-containing peptides on cyanobacteria (Takamura et al., 2004),

61 which may be a consequence of the unusual makeup of cyanobacteria cell walls (Hoiczyk and

62 Hansel, 2000).

63 Previous reports (Hare et al., 2005; Pokrzywinski et al., 2012; Tilney et al., 2014)

64 characterized the algicidal activity of bacterium Shewanella sp. IRI-160, which killed a broad

65 range of species from six families within the Dinophyta, while having no significant impact on

66 other phytoplankton. The bacterium was found to secrete a low molecular weight, water-soluble

67 compound, referred to as IRI-160AA (Pokrzywinski et al. 2012). A recent study by

68 Pokrzywinski et al. (submitted) investigated biochemical impacts of the algicide. The algicide

69 inhibited cell cycle progression in dinoflagellates, with increased intracellar and extracellular

70 ROS production, as well as increased caspase-like (DEVDase) activity, suggesting a 
71 biochemically mediated, non-necrotic cell death pathway. Tilney et al. (2014) evaluated the

72 algicide's impact on dinoflagellate physiology and observed species-specific impacts on

73 photobiology. Previous studies demonstrating growth inhibition in non-photosynthetic

74 dinoflagellates (Hare et al. 2005; Pokrzywinski et al. 2012), however, suggest that the

75 chloroplast is not the primary target of the algicide.

76 Dinoflagellates comprise a diverse group of species with varying morphological and

77 physiological features, (Spector 1984; Taylor 1987) and include representatives from trophic

78 levels ranging from strictly autotrophic to mixotrophic, parasitic, and predatory species. In

79 contrast to the large diversity in morphological and physiological characteristics, the unique

80 features of the dinoflagellate nucleus are fairly well conserved across the phylum (Spector 1984;

81 Taylor 1987) which comprises some of the largest eukaryotic genomes (Wisecaver and Hackett

82 2011). A large number of chromosomes, ranging from 24 to 220 , are required to package the

83 substantial amount of genomic material (Wisecaver and Hackett 2011). The chromosomes are

84 unusual in that they remain permanently condensed throughout the life cycle (Bhaud et al. 2000)

85 and have a low quantity of histone or basic/histone-like proteins (HLPs), which, in other

86 eukaryotes, are required for neutralizing the negative charge in the sugar-phosphate backbone of

87 DNA. Instead, there is a high proportion of metal ions in the dinoflagellate nucleus, where the

88 ratio of metal to DNA base pair is 1:1 (Sigee and Kearns 1982). Studies by Sigee and Kearns

89 (1982) and Levi-Setti et al. (2008) suggest that divalent cations, particularly calcium and

90 magnesium, and transition metals are required to neutralize the negative charge of DNA and also

91 provide structure to the permanently condensed DNA without resulting in steric hindrance. In

92 addition to metal ions, dinoflagellate DNA also has a high proportion of 5-hydroxymethyluracil

93 (5HmU), replacing 12-70 \% of thymine in their DNA (discussed in Williams and Place 2014). 
94 This modification is unique among eukaryotes, and only rarely observed in prokaryotes (Spector 95 1984; Taylor 1987; Lin 2011). The unique chromosome packaging and DNA base modifications

96 of dinoflagellates makes the nucleus an attractive target for dinoflagellate-specific algicides,

97 either through direct interaction with the algicide or through secondary impacts. Here, changes in cellular morphology of dinoflagellates were examined after short-term

99 exposure to IRI-160AA, with emphasis on identifying algicide-induced changes to the nucleus.

100 Changes in cellular morphology were initially evaluated in three dinoflagellate species,

101 Karlodinium veneficum, Prorocentrum minimum and Gyrodinium instriatum, using super

102 resolution structured illumination microscopy (SR-SIM). The ultrastructure of organelles of $K$.

103 veneficum and P. minimum were then examined using transmission electron microscopy (TEM).

104 Results of this descriptive study were consistent with the hypothesis that IRI-160AA induced 105 destabilization of chromosome structure while also showing species-specific morphological 106 changes in response to the algicide.

107

108 2. Materials and Methods

109

\subsection{Phytoplankton culture maintenance}

113 Phytoplankton strain CCMP2233, ncma.bigelow.org), Karlodinium veneficum (CCMP2396) and 114 Gyrodinium instriatum (CCMP2935). Cultures were maintained in sterile f/2 medium (Guillard 1151975 ) adjusted to a salinity of 20 and at $25^{\circ} \mathrm{C}$ with approximately $185 \mu \mathrm{mol}$ photons $\mathrm{m}^{-2} \mathrm{~s}^{-1}$ on a

116 12:12 hr light:dark cycle. All experiments were conducted on batch cultures in logarithmic stage 117 growth. None of the cultures were axenic. 


\subsection{Algicide production}

The algicide, IRI-160AA, was prepared as described in Pokrzywinski et al. (2012) with

122 the following modifications. The optical density (OD) of Shewanella sp. IRI-160 culture in LM

123 medium was measured after 18 hours using a NanoDrop 2000c (ThermoFisher Scientific,

124 Waltham, MA, USA) at $600 \mathrm{~nm}$ wavelengths. For consistency between batches, $100 \mathrm{~mL}$ of

125 culture adjusted to an OD of 1.5 was added to $900 \mathrm{~mL}$ of LM medium. The Shewanella sp. IRI-

126160 culture was incubated at $25^{\circ} \mathrm{C}$ on an orbital shaker at $100 \mathrm{rpm}$, until it again reached an OD

127 of 1.5. The culture was then centrifuged at 4,000 xg for 5 min using a Sorvall RC-5B superspeed

128 centrifuge (DuPont Instruments, Wilmington, DE, USA). The supernatant was removed and 129 cells were washed with $f / 2$ medium. The culture was resuspended in $800 \mathrm{~mL} f / 2$ medium and

130 incubated for 1 week at $25^{\circ} \mathrm{C}$. After 1 week the supernatant was harvested via centrifugation at

$1314,000 \mathrm{x} g$ for $5 \mathrm{~min}$. The cell-free supernatant was autoclaved at $121{ }^{\circ} \mathrm{C}$ for $20 \mathrm{~min}$ and was

132 further purified by passing through a C18 HYPER SEP solid phase extraction column (Thermo

133 Scientific, Waltham, MA, USA) as described in Pokrzywinski et al. (2012). Briefly, the cell free

134 algicidal supernatant was loaded onto a C18 column, the aqueous pass-through was collected and 135 the partially-purified extract was added directly to cultures at $10 \%$ final $(v / v)$. Multiple batches

136 of the algicide were produced in this way and tested individually on Karlodinium veneficum. All

137 batches used in this study exceeded $75 \%$ algicidal activity and were combined for this study to

138 ensure consistency. Aliquots of the partially-purified algicidal extract were stored at $-80{ }^{\circ} \mathrm{C}$ long

139 term (greater than 1 month) or at $10^{\circ} \mathrm{C}$ for short-term use $(<3$ weeks). Previous research by

140 Pokrzywinski et al. (2012) showed that the algicide was stable for at least three weeks at $4{ }^{\circ} \mathrm{C}$

141 and for greater than 1 year at $-80^{\circ} \mathrm{C}$. The $f / 2$ media used in this study was also loaded onto a 
$142 \mathrm{C} 18$ column, the aqueous pass-through collected and used at $10 \%$ final $(v / v)$ in algal cultures as

143 a corresponding control.

144

$145 \quad 2.3$ Cellular morphology

146

147

Short-term changes in cellular morphology of P. minimum, K. veneficum and $G$.

148 instriatum were examined using fluorescent staining with super-resolution structured

149 illumination microscopy (SR-SIM). Cells were harvested from treatment cultures $(250 \mathrm{~mL}$ final

150 volume) at $15 \mathrm{~min}$ intervals for approximately $2 \mathrm{hrs}$ after a $10 \%(v / v)$ addition of IRI-160AA.

151 Control cultures received a $10 \%(v / v)$ addition of $\mathrm{f} / 2$ medium and were harvested at the same

152 time points. At each time point, an aliquot of each culture was concentrated at 1,000 xg for 5

153 min. The supernatant was decanted and cells were resuspended in $1 \mu \mathrm{g} \mathrm{mL}^{-1}$ CellMask Orange

154 (Molecular Probes/Life Technologies, Grand Island, NY) in PBS for P. minimum and K.

155 veneficum and $1.875 \mu \mathrm{g} \mathrm{mL}^{-1}$ for $G$. instriatum. After staining with CellMask Orange, cells were

156 washed with PBS, recentrifuged and fixed in $2 \%$ (final volume) paraformaldehyde for 20 min at

$1574^{\circ} \mathrm{C}$. Cells were then centrifuged and resuspended in 2 mL DAPI solution [2 $\mu \mathrm{g} / \mathrm{mL} 4^{\prime} 6^{\prime}-$

158 diamidino-2-phenylidole (Molecular Probes/Life Technologies) in $50 \mathrm{mM} \mathrm{NaCl,} 50 \mathrm{mM}$ Tris-

$159 \mathrm{HCl} \mathrm{pH} \mathrm{7.5]} \mathrm{for} 5$ minutes in the dark. Cells were collected by centrifugation and stored in 100

$160 \mu \mathrm{L} 30 \%$ glycerol in PBS at $4{ }^{\circ} \mathrm{C}$ in the dark prior to SR-SIM.

161 Images were captured by SR-SIM on a Zeiss ELYRA PS.1 super-resolution microscope

162 (Carl Zeiss, Oberkochen, Germany) with a Plan-Apochromat 63x/1.4 oil objective. Chlorophyll

163 autofluorescence was acquired with $4 \% 642 \mathrm{~nm}$ laser and a 655 longpass filter. Chromosomes

164 labeled with DAPI were acquired with $15 \% 405 \mathrm{~nm}$ laser excitation and a $420-480 \mathrm{~nm}$

165 bandpass filter. Cell membranes labeled with CellMask Orange (Life Technologies) were 
166 acquired with $0.7 \% 561 \mathrm{~nm}$ laser power and a $570-620$ bandpass filter. Z-stacks were taken

167 using 5 phase shifts and 3 rotations of the structured illumination pattern and a $0.091 \mu \mathrm{m} \mathrm{z}$ -

168 interval. Structured illumination reconstructions were conducted with default settings in the Zen

1692011 (Carl Zeiss) processing software.

170

$171 \quad 2.4$ Cellular Ultrastructure

172

173 The ultrastructure of $P$. minimum and $K$. veneficum were examined using TEM. Images

174 of $G$. instriatum were not obtained due to the fragility of this species. A $10 \%(v / v)$ final

175 concentration in $100 \mathrm{~mL}$ cultures of IRI-160AA or $f / 2$ medium (control) was added to cultures in

176 logarithmic growth phase. After $1.5 \mathrm{hr}($ K. veneficum $)$ or $1.75 \mathrm{hr}(P$. minimum) incubation, 40

$177 \mathrm{~mL}$ of culture was concentrated by centrifugation at $1000 \mathrm{xg}$ for $5 \mathrm{~min}$ using a swinging bucket

178 centrifuge. The supernatant was discarded and cells were resuspended in $1 \mathrm{~mL}$ of $1 \%$ EM-grade

179 glutaraldehyde in PBS and incubated overnight at $4{ }^{\circ} \mathrm{C}$. The algae were again pelleted, and the

180 supernatant was removed leaving the cells in a paste-like consistency. The cell pellet was

181 transferred to either $1.2 \mathrm{~mm} \times 200 \mu \mathrm{m}$ or $1.5 \mathrm{~mm} \times 200 \mu \mathrm{m}$ high pressure freezer carriers, frozen

182 with a Leica EMPact high pressure freezer (Leica Microsystems, Wetzlar, Germany) and freeze

183 substituted in either $2 \%$ glutaraldehyde in acetone or $2 \%$ osmium tetroxide, $1 \%$ water in

184 acetone using a Leica AFS (Automated freeze substitution: Leica Microsystems). Samples were

185 freeze substituted at $-85^{\circ} \mathrm{C}$ for $118 \mathrm{hr}$ before being warmed at a rate of $4{ }^{\circ} \mathrm{C} \mathrm{hr} r^{-1}$ for $15 \mathrm{hr}$ and

186 held at $-20{ }^{\circ} \mathrm{C}$ for $5 \mathrm{hr}$. Samples were then warmed at a rate of $5{ }^{\circ} \mathrm{C} \mathrm{hr}{ }^{-1}$ for $5 \mathrm{hr}$, held at $4{ }^{\circ} \mathrm{C}$ for

$1872 \mathrm{hr}$, and transferred to room temperature for an additional $2 \mathrm{hr}$. Samples were washed with

188 anhydrous acetone and infiltrated with EMBed-812 resin (Electron Microscopy Sciences, 
189 Hatfield, PA). Samples were embedded in BEEM capsules (Electron Microscopy Sciences) and

190 polymerized at $60{ }^{\circ} \mathrm{C}$ for $24 \mathrm{hr}$. Resin-embedded samples were sectioned on a Reichert-Jung

191 Ultracut E ultramictrotome (Leica Microsystems), and ultrathin sections were collected onto

192 formvar/carbon-coated 200 mesh copper grids and post-stained with $2 \%$ alcoholic uranyl acetate

193 and Reynolds' lead citrate. Samples were imaged with a Libra 120 transmission electron

194 microscope (Carl Zeiss) at 120kV and images were acquired with a Gatan Ultrascan 1000 CCD

195 (Gatan, Inc., Pleasanton, CA, USA).

196

197 3. Results

198

1993.1 Cellular morphology

200

201

Substantial morphological changes were observed by SR-SIM in all algicide-treated

202 dinoflagellates after short-term (2hr) exposure to the algicide (Fig. 1). A typical nucleus,

203 chloroplast(s) and plasma membrane were observed in all control cells (Fig. 1A,C,E and Suppl.

204 Fig. 1A, 2A, and 3A). For Prorocentrum minimum, nine cells were imaged after exposure to the

205 algicide (representative cells shown in Fig. 1B and Suppl. Fig. 1B-C). In all images, the

206 chloroplasts appeared granular and enlarged compared to the controls (Fig. 1A, Suppl. Fig. 1A).

207 In addition, the DNA was expelled from several of the imaged cells treated with the algicide

208 (Suppl. Fig. 1B), while the cell and theca appeared intact. At each time point after exposure,

209 cells were observed with a low apparent quantity of DNA and lack of chromosomal structure,

210 while some cells were anucleated (Suppl. Fig. 1C) with chromosomal DNA at the periphery of

211 the cell (Fig. 1B) or outside of the cell (Suppl. Fig. 1B). 
Fourteen cells were imaged for $K$. veneficum after exposure to the algicide (represented

213 by Fig. 1D and Suppl. Fig. 2B-G). The cellular membrane of algicide-treated cells appeared

214 intact at all time points for the $2 \mathrm{hr}$ experiment. The lipophilic membrane stain, CellMask orange

215 (shown in green for contrast) was taken up by K. veneficum in both control and treated cells, so

216 that internal membranes were also stained (Fig. 1C-D; Suppl. Fig. 2A-G). Lipid stained

217 structures within the chloroplasts of both controls and treatments may represent a pyramidal

218 pyrenoid (PP) in this species (discussed in Garcés et al. 2006). After short-term (2 hrs) exposure

219 with IRI-160AA, there was an apparent increase in chloroplast volumes in K. veneficum (Suppl.

220 Fig. 2C,E,G). The nucleus appeared to remain intact but elongation of the nucleus was observed

221 in some of the cells after exposure to the algicide (Suppl. Fig. 2D-G) and was more obvious at

222 later time points. In addition, the nucleus and chloroplasts were translocated to the periphery of

223 the cell, often appearing as a bulge in the cell membrane (Suppl. Fig. 2B,D,F,G). Blebs were

224 observed on the surface of the cellular membrane and formed around organelles that had

225 migrated to the periphery.

226 Seven cells were imaged for algicide-treated G. instriatum (represented by Fig. 1F,

227 Suppl. Fig. 3B-C). Short-term exposure of G. instriatum to the algicide resulted in increased cell

228 size compared to controls (Fig. 1E-F). The cellular membrane of this athecate species remained

229 intact in all images acquired, with blebs visible on the surface of several cells (Suppl. Fig. 3B-C).

230 The chloroplasts appeared granular and compacted but with an apparent increase in volume

231 compared to the control in all micrographs. The observed increase in cell size may be due to

232 noticeable nuclear expansion in several of the images (Fig. 1F, Suppl. Fig. 3B-C). Additionally,

233 there was an apparent decompaction and/or fragmentation of the chromosomes, as seen in Fig.

$2341 \mathrm{~F}$. In contrast to $K$. veneficum and $P$. minimum, the DNA was ejected from the cell in only one 
235 of the seven images obtained.

2373.2 Cellular Ultrastructure

240 minimum (Fig. 2-3). Ten images were obtained for control cells. Chloroplasts were located in

241 the periphery of the cell, beneath the thecal plate and in many cases included a compound intra-

242 chloroplast pyrenoid (Fig. 2A). The nucleus was centrally located and contained condensed

243 chromosomes with distinct banding patterns composed of fibrils and granules (Fig. 2B-C).

244 Trichocysts (extrusomes), which were square in cross-section, were located just under the plasma

245 membrane (Fig. 2A). Cells also contained fibrous vesicles in the anterior region of the cell near

246 the flagellar apparatus (Fig. 2A and 3C). In algicide-treated cells of P. minimum (19 images

247 total), there was increased vacuolization in the cytoplasm (Fig. 2D). The nucleoplasm appeared

248 less granular than the control cells (Fig. 2E). The nuclear membrane had broken down in places

249 and chromosomes appeared partially or wholly outside of the nucleus (Fig. 2E-F). The fibrils

250 and granules of chromosomes became less apparent and the edges of chromosomes became less

251 distinct, indicative of chromosome decompaction (Fig. 2D-F). Electron-dense aggregates, likely

252 ribosomes, appeared in vacuoles (Fig. 2D). There were minimal observable changes in the

253 ultrastructure of mitochondria (less apparent cristae) in algicide-treated cells compared to

254 controls (Fig. 3B,E). Greater changes were observed in chloroplasts, mitochondria and fibrous

255 vesicles of P. minimum cells exposed to IRI-160AA (Fig. 3D-F) compared to controls (Fig. 3A-

256 C). Chloroplasts contained more inter-thylakoid electron dense regions in algicide-treated cells

257 (Fig. 3D) compared to controls (Fig. 3A). Most noticeable were regions where the inter-

258 thylakoid space of algicide-treated cells had expanded and contained electron depleted regions 
259 (Fig. 3D). Mitochondria were slightly enlarged, circular and also contained electron depleted 260 regions (Fig 3E). After IRI-160AA treatment, the fibrous vesicles no longer had an organized

261 pattern and appeared to contain fewer fibers (Fig. 3F) compared to controls (Fig. 3C).

262 The ultrastructure of $K$. veneficum after algicide treatment was also examined using TEM

263 (Fig. 4-5). Twelve images were obtained for K. veneficum control cells (represented by Fig. 4A-

264 C). In each, the chloroplasts were located in the periphery of the cell, just under the plasma

265 membrane and contained thylakoids in stacks of three (Fig. 5A), as typical of a plastid derived

266 from a tertiary endosymbiotic event (Morden and Sherwood 2002). The pyramidal pyrenoid

267 (PP) was located in the chloroplast and did not have thylakoids. The mitochondria were

268 observed with tubular cristae (Fig. 4A and 5C). Vacuoles were distributed throughout the

269 cytoplasm. Aggregates of electron-dense granules, likely ribosomes, were distributed throughout

270 the cytoplasm. The nuclei of $K$. veneficum control cells were centrally located in the cell and had

271 electron dense chromosomes with a characteristic banding pattern typical of dinoflagellate

272 chromosomes, and contained regularly spaced fibrils and granules (Fig. 4A-C). In algicide-

273 treated cells of $K$. veneficum (12 images total, Fig. 4D), amphiesmal and nuclear membrane

274 blebbing were visible. The nucleus and chloroplasts were relocated to opposite ends of the cell,

275 consistent with images obtained with SR-SIM. This may be due to the presence of a large

276 vacuole that had filled the inter-organelle space in the cytoplasm. The chloroplasts and PP were

277 more spherical compared to the controls, while thylakoids were unchanged (Fig. 4A,D and 5B).

278 Electron-dense aggregates were also visible in treated cells (Fig. 4D). The arches of

279 chromosomes appeared more fibrous in algicide-treated cells of $K$. veneficum, suggesting that the 280 algicide may have an effect on processes occurring in the perichromosomal layer (Fig. 4E,F). 


\section{Discussion}

The study presented here evaluated the effects of algicide IRI-160AA on morphology of three dinoflagellate species, $P$. minimum, $K$. veneficum and $G$. instriatum. In all cases, impacts on the nucleus were consistent with disruption of chromosome structure. Observed algicidal

287 effects, however, were species-specific (Fig. 6). In algicide treated K. veneficum the

288 chromosomes were apparent at all times but the nuclei were translocated to the periphery of the 289 cell, at times forming a bulge in the cell membrane (Fig. 1D and Suppl. Fig. 2B-G).

290 Chromosomes of algicide-treated cells also appeared to be elongated and fixed in an anaphase 291 like state at later time points (Suppl. Fig. 2D-G) (Soyer-Gobillard et al. 1990) while the nuclei 292 and chromosomes of control cells remained unchanged over the course of this study (2 hours).

293 In contrast, algicide-treated cells of $G$. instriatum showed considerable nuclear expansion, with 294 decompaction of the chromosomes so that they appeared to be "unraveling" (Fig. 1F). The 295 nuclear membrane also disintegrated in some cells of G. instriatum, allowing the DNA of this 296 species to fill the cytosolic space (Suppl. Fig. 3C). In P. minimum, the impacts of the algicide on 297 the nucleus were more variable. Cells were observed with chromosomes translocated to the 298 periphery of the cell (Fig. 1B) or ejected from the cell (Suppl. Fig. 1B), resulting in anucleated 299 cells in some cases (Suppl. Fig. 1C). Although TEM images for $G$. instriatum were not obtained, ultrastructural images of $K$.

301 veneficum and $P$. minimum confirmed significant impacts to chromosomes in these algicide 302 treated cultures. Dinoflagellates have liquid crystalline chromosomes (LCCs), which are 303 composed of a highly condensed core and transcriptionally active DNA loops that decondense at 
304 the periphery of the chromosome (Oakley and Dodge 1979; Cachon et al. 1989; Minsky et al.

305 1997; Oldenbourg et al. 1998; Livolant et al. 2006). In the absence of nucleosomes, these

306 peripheral transcriptional loops are maintained through the dense structure of the LCCs in the

307 core DNA (Chow et al. 2010). Although the ratio of DNA to HLP ratio is low in dinoflagellates,

308 HLPs are essential in these species to maintain the extrachromosomal loops for transcription by

309 actively straightening DNA in the periphery of chromosomes (Chan and Wong 2007). The

310 mechanism by which transcription occurs on these whorls remains largely unknown (Sigee,

311 1984, 1986; Soyer-Gobillard et al., 1990; Rizzo, 1991; discussed in Beauchemin et al. 2012).

312 TEM analysis of the nucleus in K. veneficum showed electron dense chromosomes with poorly

313 identifiable banding patterns (Fig. 4E,F). In addition, the edges of chromosomes appeared more

314 fibrous, suggesting that the impact of the algicide on the structural integrity of chromosomes

315 may be interfering with transcription (Sigee 1984, 1986; Soyer-Gobillard et al. 1990; Rizzo

316 1991). Electron micrographs of $P$. minimum also revealed abnormal nuclear morphologies,

317 including the decompaction and subsequent expulsion or "leakage" of chromosomes into the

318 cytosol (Fig. 2E-F), possibly at the site of nuclear pores (visible in the control Fig. 2A).

319 Expulsion may be driven by the mechanical force associated with chromosome decompaction, in 320 a manner similar to expulsion of viral DNA (Tzlil et al. 2003).

321 In all three species examined here, substantial changes to the chloroplasts were also

322 noted. Chloroplasts were relocated to the periphery of the cell after algicide treatment, possibly

323 as a result of increased vacuolization and nuclear expansion. Analysis of electron micrographs

324 of $P$. minimum and $K$. veneficum revealed changes in chloroplast shape, with plastids in algicide-

325 treated cells appearing more spherical than in controls. Similar changes in chloroplast structure

326 were noted in Arabidopsis thaliana after exposure to the plant stress hormone methyl jasminate 
327 (Zhang and Xing 2008) and were attributed to ROS production. Likewise, Pokrzywinski et al.

328 (submitted) showed that exposure to the algicide resulted in significant increases in both intra-

329 and extracellular ROS production, measured at 3 hours and over a 24-hour period, respectively.

330 In spite of the clear impact on dinoflagellate chromosomes and chloroplasts, however, it is

331 unclear from this study which of these is the proximal target of the algicide or if changes in

332 nuclear and/or chloroplast structures represent secondary, downstream impacts. Hare et al.

333 (2005) and Pokrzywinski et al. (2012) examined algicidal impacts of IRI-160AA on a range of

334 dinoflagellates including heterotrophs Pfiesteria piscicida, which acquires chloroplasts through

335 kleptochlorplasty (Lewitus et al., 1999), and Oxyrrhis marina. These studies demonstrated no

336 significant differences in growth inhibition between heterotrophic dinoflagellates and

337 phototrophic species after exposure to Shewanella IRI-160 (Hare et al., 2005) or to the algicidal

338 filtrate (Pokrzywinski et al., 2012), and suggest that impacts observed on chloroplasts in this

339 investigation are likely secondary to those on the nucleus.

340

\section{5. Conclusions}

342 Exposure to the algicide IRI-160AA produced by marine bacterium Shewanella sp. IRI-

343160 resulted in significant morphological changes in dinoflagellates. Changes to the nucleus and

344 chloroplasts were most apparent, but the proximal target of the algicide was not identified here.

345 In all cases, changes in cellular morphology and ultrastructure were observed within two hours,

346 suggesting that the algicide may be an effective approach to quickly mitigate dinoflagellate

347 blooms. Future work should focus on isolation and characterization of the algicidal compound,

348 IRI-160AA. 
350

351

352

353

354

355

356

357

358

\section{Acknowledgements}

This work was supported by the National Oceanic and Atmospheric Association (NOAA)

Prevention, Mitigation and Control of HABs (PCM HAB) program (Grant \# NA10NOS4780136

to KJC and MEW, contribution number PCM034). This work was also made possible by the National Science Foundation EPSCoR Grant No. IIA-1301765 and the State of Delaware. 


\section{References}

360

361 Beauchemin, M., Roy, S., Daoust, P., Dagenais-Bellefeuille, S., Bertomeu, T., Letourneau, L.,

362 Lang, B.F., Morse, D., 2012. Dinoflagellate tandem array gene transcripts are highly conserved 363 and not polycistronic. PNAS. 109(39): 15793-15798.

365 Bhaud, Y., Guillebault, D., Lennon, J., Defacque, H., Soyer-Gobillard, M.O., Moreau, H., 2000.

366 Morphology and behaviour of dinoflagellate chromosomes during the cell cycle and mitosis. J.

367 Cell. Sci. 113(7): 1231-1239.

368

369 Bidle, K.D., Falkowski, P.G., 2004. Cell death in planktonic, photosynthetic microorganisms.

370 Nat. Rev. Microbiol. 2(8): 643-655.

371

372 Cachon, J., Sato, H., Cachon, M., Sato, Y., 1989. Analysis by polarizing microscopy of

373 chromosomal structure among dinoflagellates and its phylogenetic involvement. Biol. Cell.

$374 \quad 65: 51-60$.

375

376 Chan, Y.H., Wong, J.T.Y., 2007. Concentration-dependent organization of DNA by the

377 dinoflagellate histone-like protein HCc3. Nucleic Acids Res. 35:2573-2583

378

379 Chow, M.H., Yan, K.T., Bennett, M.J., Wong, J.T., 2010. Birefringence and DNA condensation 380 of liquid crystalline chromosomes. Eukaryotic Cell 9(10):1577-1587. 
381 Fukami, K., Nishijima, T., Ishida, Y., 1997. Stimulative and inhibitory effects of bacteria on the 382 growth of microalgae. Hydrobiologia 358, 185-191.

383

384 Garcés, E., Fernandez, M., Penna, A., Van Lenning, K., Gutierrez, A., Camp, J., Zapata, M., 385 2006. Characterization of NW Mediterranean Karlodinium spp. (Dinophyceae) strains using 386 morphological, molecular, chemical, and physiological methodologies. J. Phycol. 42: 1096-1112.

387 DOI: $10.1111 / \mathrm{j} .1529-8817.2006 .00270 . \mathrm{x}$

388

389 Guillard, R.R.L., 1975. Culture of Phytoplankton for Feeding Marine Invertebrates. In: Smith 390 WL, Chanley MH [Eds.], Culture of Marine Invertebrate Animals. Plenum Press, New York, pp. $39126-60$.

392

393 Hare, C.E., Demir, E.D., Coyne, K.J., Cary, S.C., Kirchmen, D.L., Hutchins, D., 2005. A

394 bacterium that inhibits the growth of Pfiesteria piscicida and other dinoflagellates. Harmful 395 Algae 4(2): 221-234.

396

397 Hoiczyk, E., Hansel, A., 2000. Cyanobacterial cell walls: news from an unusual prokaryotic 398 envelope. Journal of Bacteriology 182(5):1191-1199.

399

400 Inaba, N., Watanabe, T., Sakami, T., Nishi, H., Tahara, Y., Imai, I., 2014. Temporal and spatial 401 distribution of algicidal and growth-inhibiting bacteria in the coastal sea of southwest Japan. J 402 Plankton Res 36(2), 388-397. 
404 Kim, M.C., Yoshinaga, I., Imai, I., Nagasaki, K., Itakura, S., Ishida, Y., 1998. A close

405 relationship between algicidal bacteria and termination of Heterosigma akashiwo

406 (Raphidophyceae) blooms in Hiroshima Bay, Japan. Mar Ecol-Prog Ser 170, 25-32.

407

408 Levi-Setti, R., Gavrilov, K.L., Rizzo, P.J., 2008. Divalent cation distribution in dinoflagellate

409 chromosomes imaged by high-resolution ion probe mass spectrometry. Eur. J. Cell. Bio. 87: 963-

410976.

411

412 Lewitus, A.J., Glasgow, H.B., Burkholder, J.M., 1999. Kleptoplastidy in the toxic dinoflagellate

413 Pfiesteria piscicida (Dinophyceae). J Phycol 35(2), 303-312.

414

415 Li, Z.H., Lin, S.Q., Liu, X.L., Tan, J., Pan, J.L., Yang, H., 2014. A freshwater bacterial strain,

416 Shewanella sp Lzh-2, isolated from Lake Taihu and its two algicidal active substances,

417 hexahydropyrrolo[1,2-a]pyrazine-1,4-dione and 2, 3-indolinedione. Appl Microbiol Biot 98(10),

$418 \quad 4737-4748$.

419

420 Lin, S., 2011. Genomic understanding of dinoflagellates. Research in Microbiology 162: 551-

421569.

422

423 Liu, J.Q., Lewitus, A.J., Kempton, J.W., Wilde, S.B., 2008a. The association of algicidal bacteria 424 and raphidophyte blooms in South Carolina brackish detention ponds. Harmful Algae 7(2): 184425193.

426 
427 Liu, J.Q., Lewitus, A.J., Brown, P., Wilde, S.B., 2008b. Growth-promoting effects of a

428 bacterium on raphidophytes and other phytoplankton. Harmful Algae 7(1): 1-10.

429

430 Livolant, F., Mangenot, S., Leforestier, A., Bertin, A., de Frutos, M., Raspaud, E., Durand, D., 431 2006. Are liquid crystalline properties of nucleosomes involved in chromosome structure and 432 dynamics? Philos. Trans. R. Soc. Lond. A Math. Phys. Eng. Sci. 364: 2615-2633.

433

434 Lovejoy, C., Bowman, J.P., Hallegraeff, G.M., 1998. Algicidal effects of a novel marine 435 Pseudoalteromonas isolate (class Proteobacteria, gamma subdivision) on harmful algal bloom 436 species of the genera Chattonella, Gymnodinium, and Heterosigma. Appl Environ Microb 64(8), $437 \quad 2806-2813$.

438

439 Mayali, X., Azam, F., 2004. Algicidal bacteria in the sea and their impact on algal

440 blooms. J. Eukaryot. Microbiol. 51(2): 139-144.

441

442 Minsky, A., Ghirlando, R., Reich, Z., 1997. Nucleosomes: a solution to crowded intracellular 443 environment? J. Theor. Biol. 188: 379-385.

444

445 Morden, C.W., Sherwood, A.R., 2002. Continued evolutionary surprises among dinoflagellates.

446 PNAS. 99(18): 11558-11560.

447

448 Oakley, B.R., Dodge, J.D., 1979. Evidence for a double-helically coiled toroidal chromonema in 449 the dinoflagellate chromosome. Chromosoma. 70: 277-291. 
451 Oldenbourg, R., Salmon, E.D., Tran, P.T., 1998. Birefringence of single and bundled

452 microtubules. Biophys. J. 74: 645-654.

453

454 Pokrzywinski, K.L., Place, A.R., Warner, M.E., Coyne, K.J., 2012. Investigation of the algicidal 455 exudate produced by Shewanella sp. IRI-160 and its effect on dinoflagellates. Harmful Algae 19: $456 \quad 23-29$.

457

458 Rizzo, P.J., 1991. The enigma of the dinoflagellate chromosome. J. Protozool. 38: 246-252.

459

460 Sakata, T., Yoshikawa, T., Nishitarumizu, S., 2011. Algicidal activity and identification of an 461 algicidal substance produced by marine Pseudomonas sp. C55a-2. Fisheries Sci 77(3), 397-402.

462

463 Sigee, D.C., Kearns, L.P., 1982. X-ray microanalysis of unfixed chromatin in dinoflagellate cells 464 prepared by a monolayer cryotechnique. J. Biochem. Biophys. Methods 6: 23-30.

465

466 Sigee, D.C., 1984. Structural DNA and genetically active DNA in dinoflagellate chromosomes.

467 BioSystems 16: 203-210.

468

469 Sigee, D.C., 1986. The dinoflagellate chromosome. Advances in Botanical Research. 12: 205470264.

471

472 Skerratt, J.H., Bowman, J.P., Hallegraeff, G., James, S., Nichols, P.D., 2002. Algicidal bacteria 
473 associated with blooms of a toxic dinoflagellate in a temperate Australian estuary. Mar. Ecol.

474 Prog. Ser. 244: 1-15.

475

476 Soyer-Gobillard, M.O., Géraud, M.L., Coulaud, D., Barray, M., Théveny, B., Révet, B., Delain,

477 E., 1990. Location of B- and Z-DNA in the chromosome of a primitive eukaryote dinoflagellate.

478 J. Cell. Biol. 111: 293-308.

479

480 Spector, D.L., 1984. Dinoflagellate nuclei. In D. L. Spector [ed.]: Dinoflagellates. Academic

481 Press, Inc., Orlando, FL, USA, pp. 107-147.

482

483 Takamura, Y., Yamada, T., Kimoto, A., Kanehama, N., Tanaka, T., Nakadaira, S., Yagi, O., 484 2004. Growth inhibition of Microcystis cyanobacteria by L-lysine and disappearance of natural 485 Microcystis blooms with spraying. Microbes and Environments, 19(1), 31-39.

486

487 Taylor, F.J.R., 1987. The Biology of Dinoflagellates. Wiley, Johns \& Sons, Inc. Hoboken, NJ, 488 USA.

489

490 Tilney, C.L., Pokrzywinski, K.L., Coyne, K.J., Warner, M.E., 2014. Growth, death and 491 photobiology of dinoflagellates (Dinophyceae) under bacterial-algicide control. J. Appl. Phycol. 492 26: 2117-2127. DOI 10.1007/s10811-014-0248-z

493

494 Tzlil, S., Kindt, J.T., Gelbart, W.M., Ben-Shaul, A., 2003. Forces and pressures in DNA 495 packaging and release from viral capsids. Biophys. J. 84:1616-1627. 
497 Williams, E.P. and Place, A.R. (2014). The role of 5-hydroxymethyl uracil in the evolution of the

498 dinokaryon.Kim, H.G., B. Reguera, G. Hallegraeff, C.K. Lee, M.S. Han and J.K Choi

499 (eds). Harmful Algae 2012, Proceedings of the 15th International Conference on Harmful

500 Algae. International Society for the Study of Harmful Algae 2014, Copenhagen, ISBN 978-87-

501 990827-4-2. pp 153-156.

502

503 Wisecaver, J.H., Hackett, J.D. 2011. Dinoflagellate genome evolution. Annu. Rev. Microbiol.

504 65: 369-387.

505

506 Yoshinaga, I., Park, J.H., Nishikawa, T., Imai, I., 2010. Algicidal bacteria in particle-associated

507 form and in free-living form during a diatom bloom in the Seto Inland Sea, Japan. Aquat Microb

508 Ecol 60(2), 151-161.

509

510 Zhang, L., Xing, D., 2008. Methyl jasmonate induces production of reactive oxygen species and

511 alterations in mitochondrial dynamics that precede photosynthetic dysfunction and subsequent

512 cell death. Plant Cell. Physiol. 49: 1092-1111.

513

514 Zheng, T.L.L., Bai, S.J.J., Huang, L.P.P., Su, J.Q.Q., Tian, Y., 2011. Algicidal effects of a novel

515 marine actinomycete on the toxic dinoflagellate Alexandrium tamarense. Curr Microbiol 62(6), $516 \quad 1774-1781$.

517 


\section{Figure Legends:}

521

522 Fig. 1: Super resolution images of dinoflagellate cellular morphologies after short-term exposure

523 to $10 \%(v / v)$ IRI-160AA. Control cells (left panel) and algicide-treated cells (right panel) for

524 Prorocentrum minimum (A and B), Karlodinium veneficum (C and D) and Gyrodinium

525 instriatum (E and F). Cells were stained with the nuclear dye DAPI and membrane dye Cell

526 Mask Orange (shown in green for contrast).

527

528 Fig. 2: Electron micrographs of Prorocentrum minimum. Cellular (A, C) and chromosome (B, 529 D) ultrastructure after exposure to IRI-160AA (C-D) are shown with respective controls for 530 comparison $(\mathrm{A}-\mathrm{B}) . \mathrm{N}=$ nucleus, $\mathrm{Ch}=$ chloroplast, $\mathrm{Py}=$ pyrenoid, $\mathrm{S}=$ starch, $\mathrm{M}=$ mitochondria, $531 \mathrm{CB}=$ cajal body, $\mathrm{Th}=$ theca, $\mathrm{V}=$ vacuole, $\mathrm{ER}=$ endoplasmic reticulum, $\mathrm{T}=$ trichocyst, $\mathrm{R}=$

532 ribosome aggregate, $\mathrm{G}=$ golgi, $\mathrm{FV}=$ fibrous vesicles and $\mathrm{Cr}=$ chromosome. Scale bar is $1 \mu \mathrm{m}$ in 533 panels A and D and $0.2 \mu \mathrm{m}$ in panels B, C, E and F. Arrows in B indicate fibrils and granules.

534 The arrow in D indicates loss of chromosomal structure and partial expulsion from the nucleus.

535

536 Fig. 3: Electron micrographs of Prorocentrum minimum chloroplast (A, D), mitochondria (B, E)

537 and fibrous vesicles (C, F) after treatment with IRI-160AA (D, E, F) with respective controls for 538 comparison (A, B, C). Scale bar is $0.2 \mu \mathrm{m}$.

539

540 Fig. 4: Electron micrographs of Karlodinium veneficum. Cellular (A, D) and chromosome (B-C,

541 E-F) ultrastructure for IRI-160AA-treated cells (D-F) are shown with respective controls for

542 comparison $(\mathrm{A}-\mathrm{C}) . \mathrm{N}=$ nucleus, $\mathrm{Ch}=$ chloroplast, $\mathrm{S}=$ starch, $\mathrm{M}=$ mitochondria, $\mathrm{V}=$ vacuole, 
$543 \mathrm{PP}=$ pyramidal pyrenoid, $\mathrm{Th}=$ theca, $\mathrm{Am}=$ amphiesmal, $\mathrm{CB}=$ cajal body, $\mathrm{R}=$ ribosome

544 aggregate, $\mathrm{T}=$ trichocyst, $\mathrm{Bl}=$ bleb and $\mathrm{Cr}=$ chromosome. Scale bar is $1 \mu \mathrm{m}$ in $\mathrm{A}$ and $\mathrm{D}$ and 0.2

$545 \mu \mathrm{m}$ in B and E. C and F are magnifications of panels B and E, respectively. Arrows in C indicate

546 fibrils and granules. Arrow in F indicates fibrous protrusions in the perichromosomal space.

547

548 Fig. 5: Electron micrographs of Karlodinium veneficum chloroplast (A-B) and mitochondria (C-

549 D) ultrastructure after exposure to IRI-160AA (B, D) with respective controls for comparison (A,

550 C). Scale bar is $1 \mu \mathrm{m}$ in panels $\mathrm{A}$ and $\mathrm{B}$ and $0.5 \mu \mathrm{m}$ in panels $\mathrm{C}$ and $\mathrm{D}$.

551

552 Fig. 6: Super resolution images of characteristic chromosome/nuclear morphologies in

553 dinoflagellates. Nuclear morphologies for Prorocentrum minimum (A-B), Karlodinium

554 veneficum (C-D) and Gyrodinium instriatum (E-F) after exposure to $10 \%(v / v)$ IRI-160AA (B,

555 D, F) with respective controls for comparison (A, C, E). Scale bars are $50 \mu \mathrm{m}(\mathrm{A}-\mathrm{C}, \mathrm{E}), 33 \mu \mathrm{m}$

556 (D) or $100 \mu \mathrm{m}(\mathrm{F})$.

557 


\section{Prorocentrum minimum}

A

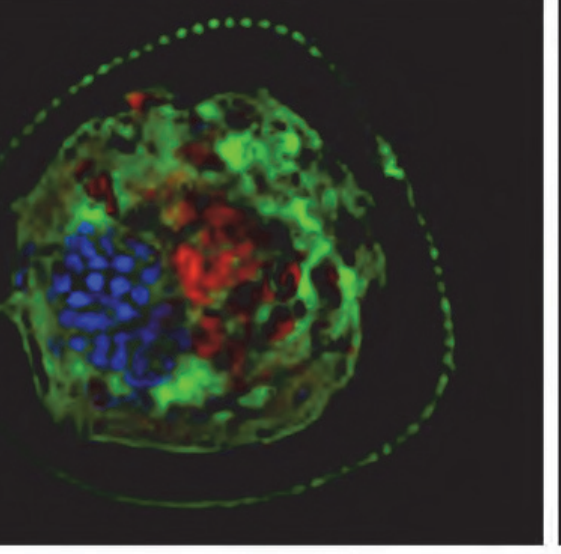

B

Karlodinium veneficum

C

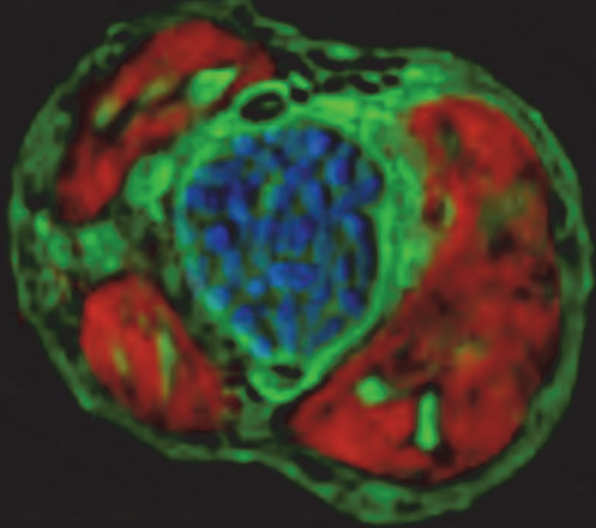

D

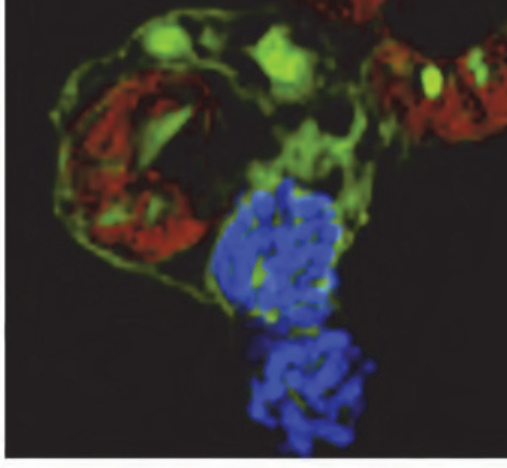

\section{Gyrodinium instriatum}

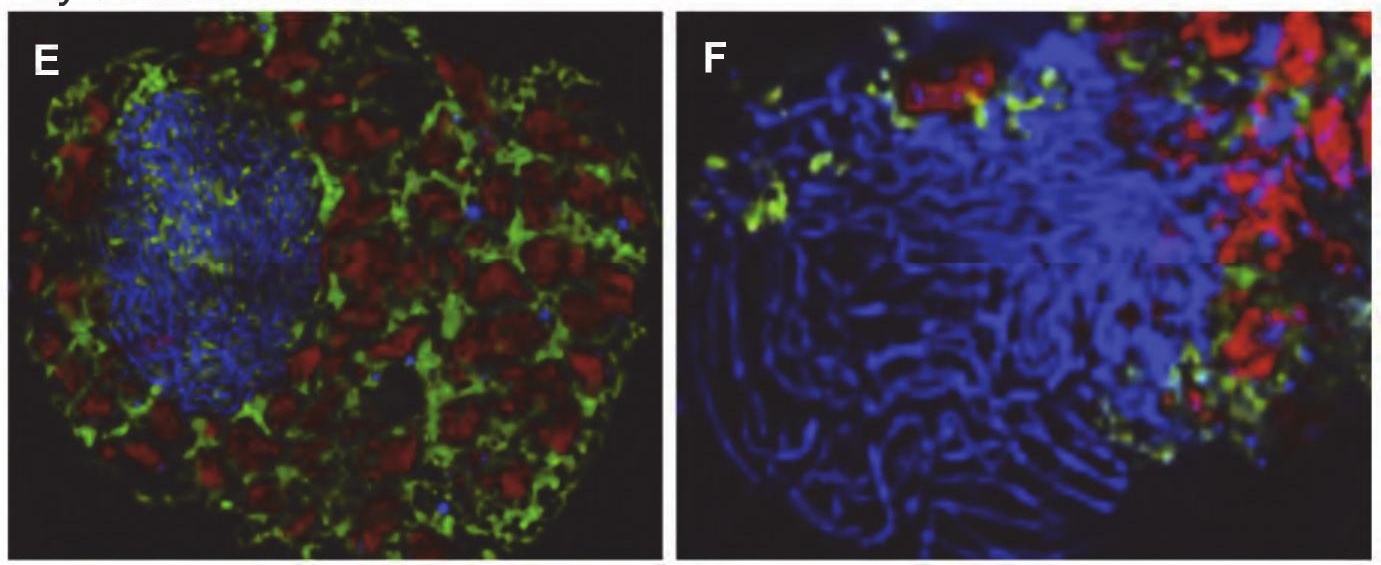




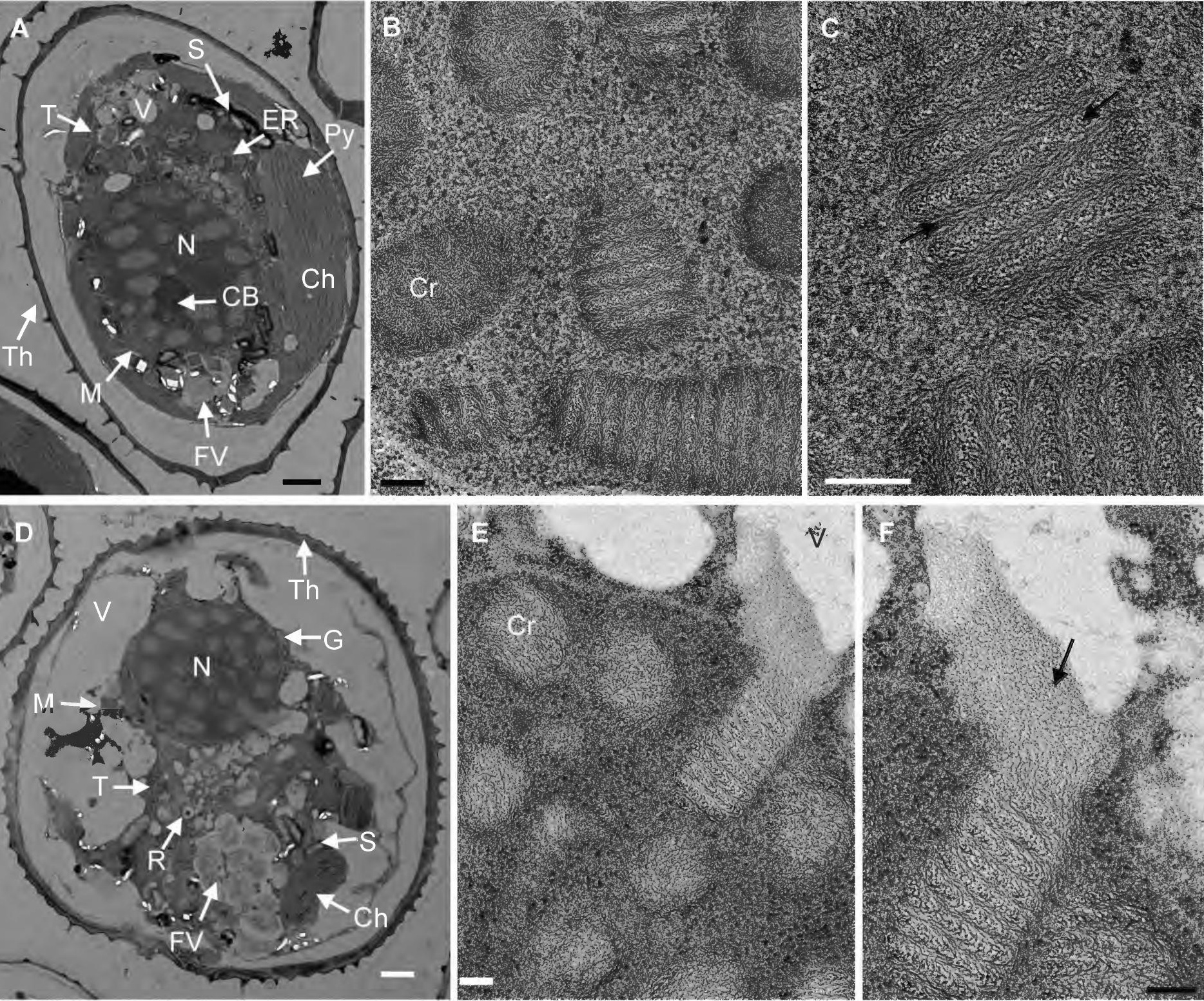




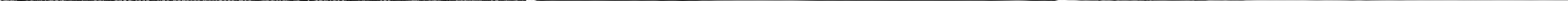




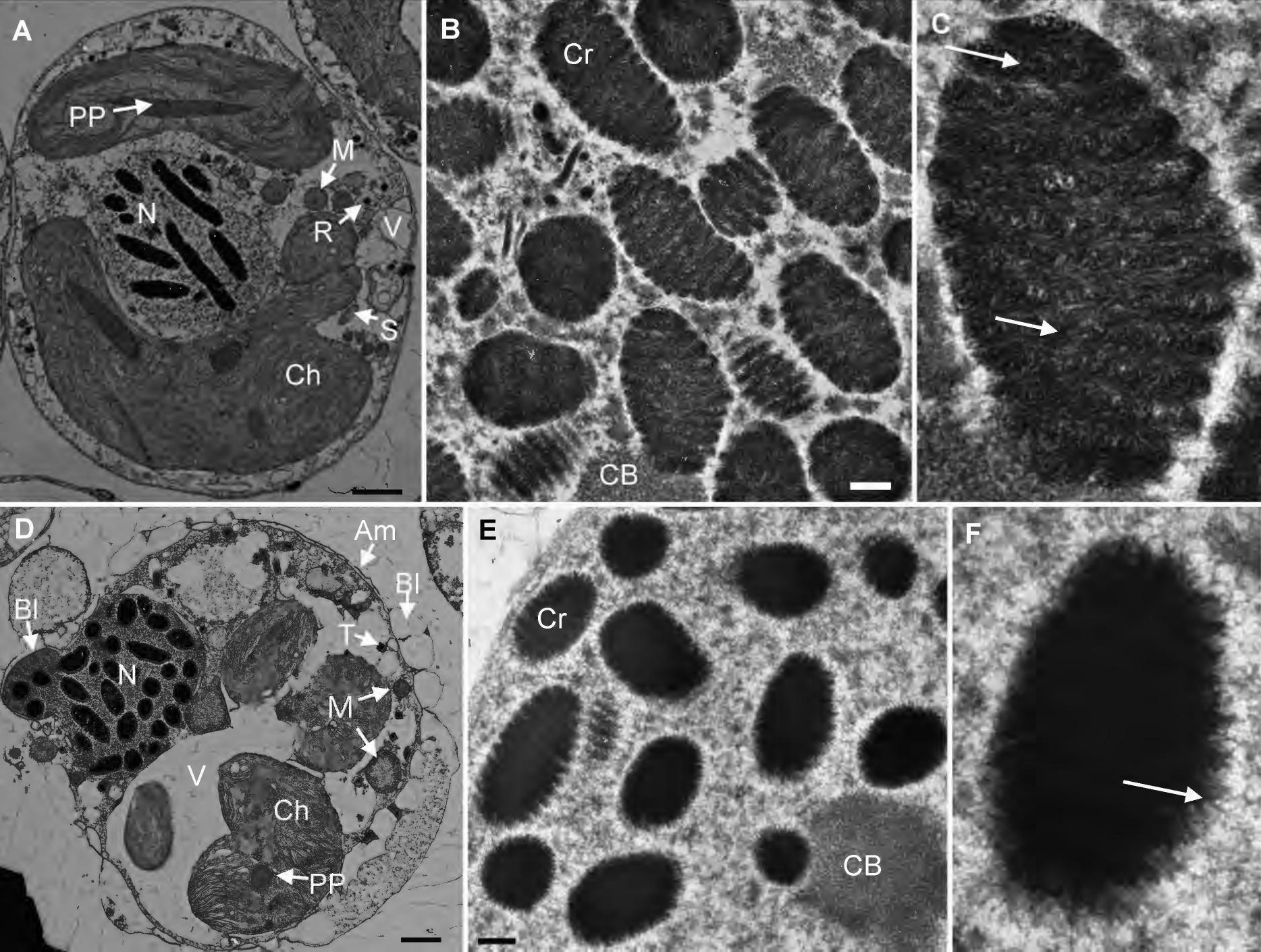




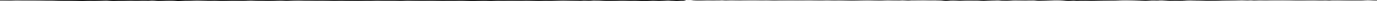


A

B
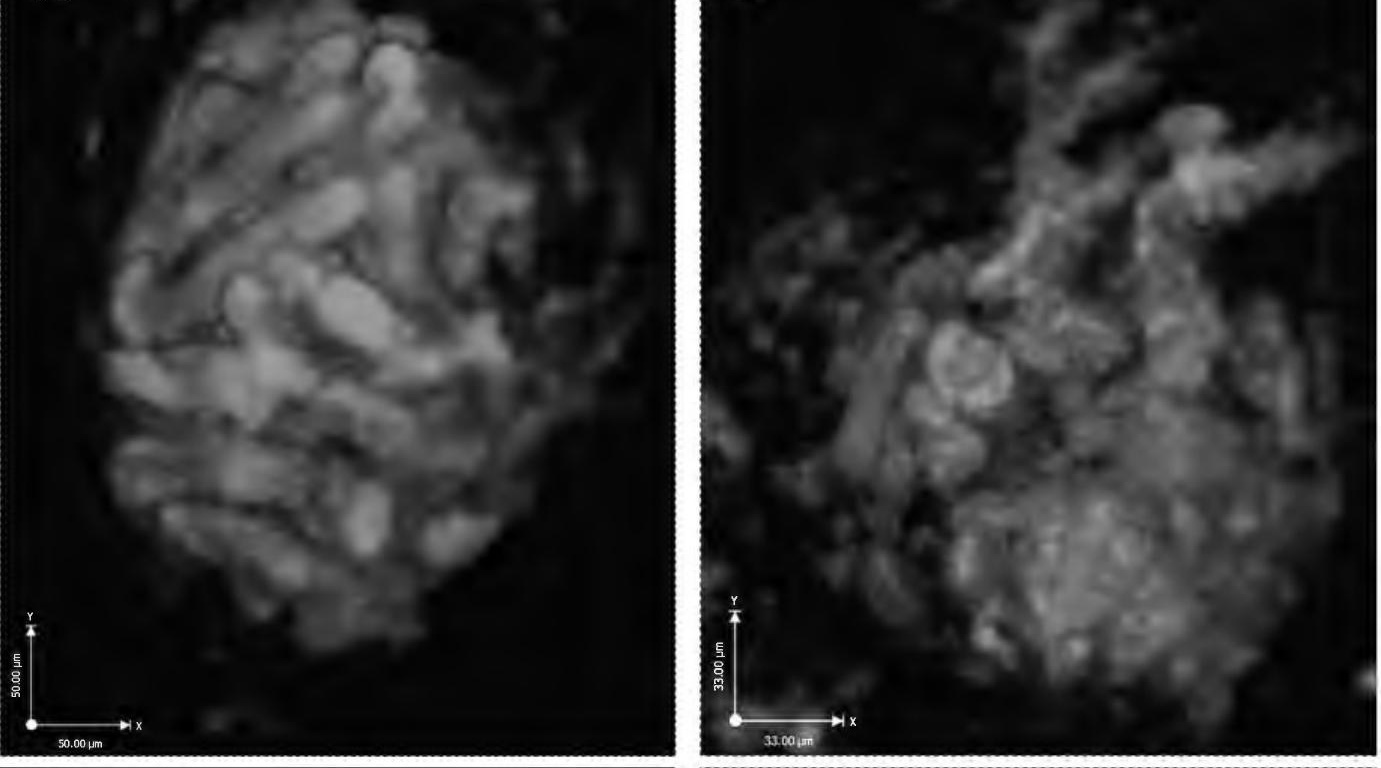

ic

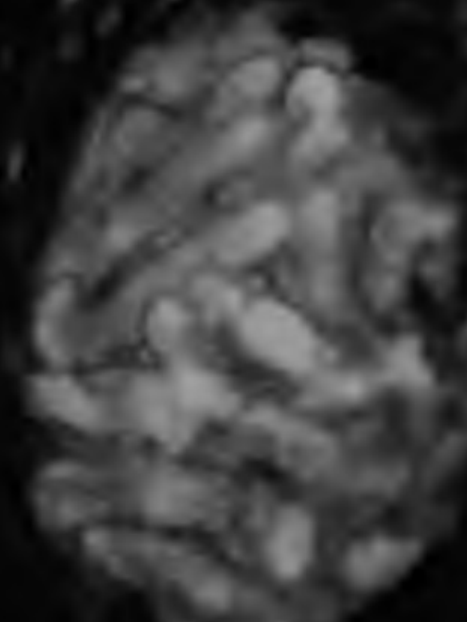

\section{B}

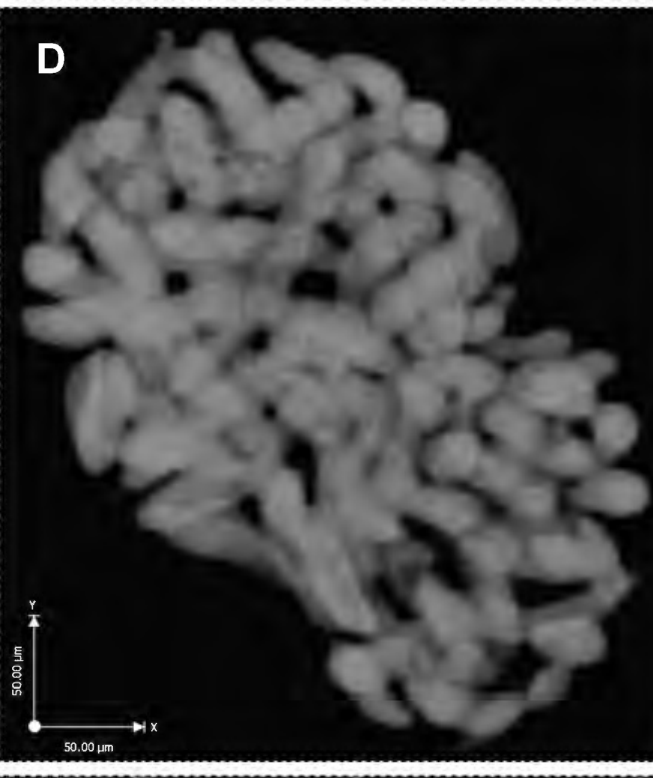

E

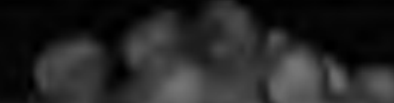

$\frac{1}{x}$
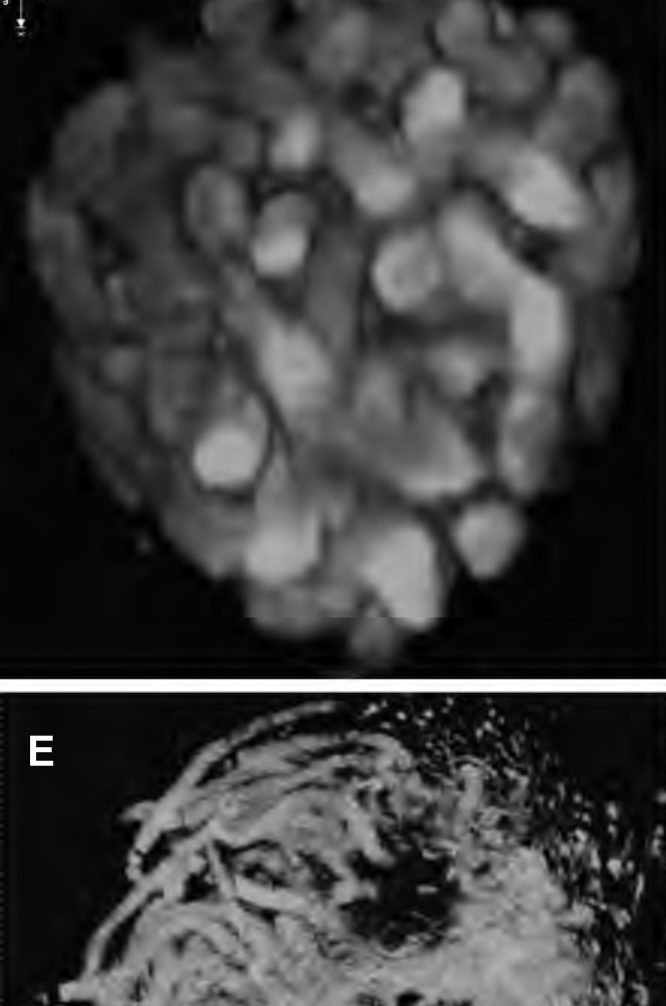

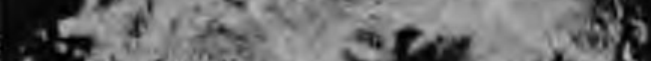

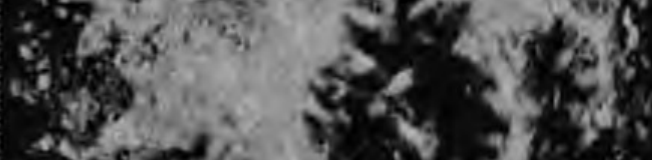

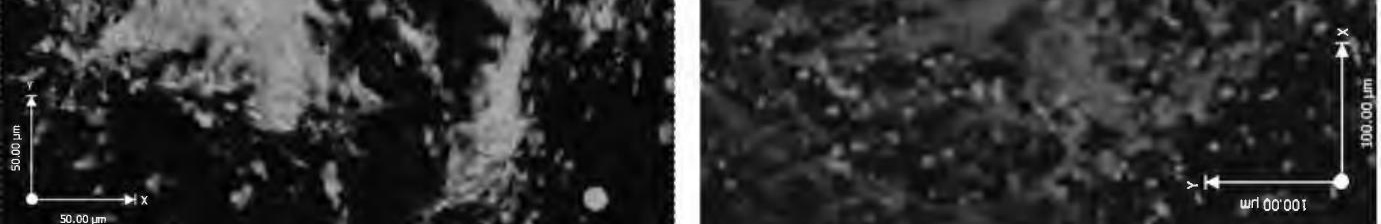

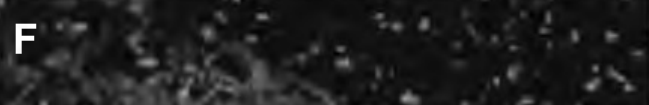

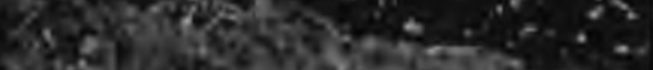

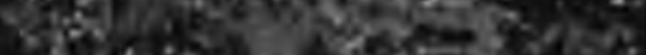

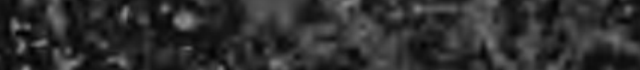

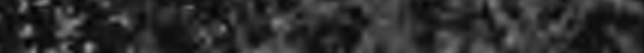

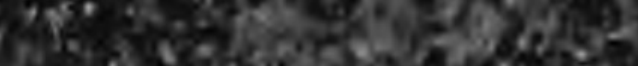

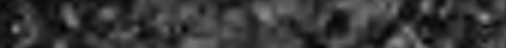
C.

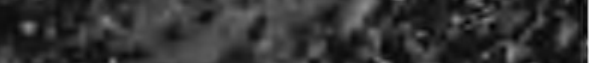

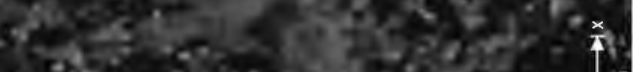

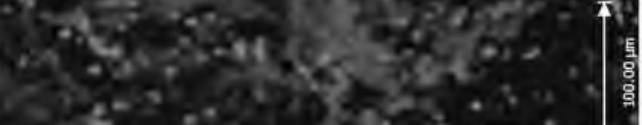

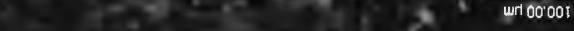

